\title{
Illicit Tobacco Product
}

National Cancer Institute

\section{Source}

National Cancer Institute. Illicit Tobacco Product. NCI Thesaurus. Code C122666.

A product containing or derived from tobacco that is not compliant with legislative requirements. 